\title{
UNA APROXIMACIÓN ANALÍTICA A LOS ASPECTOS DE LA FORMA Y EL MOVIMIENTO
}

\author{
AN ANALYTIC APPROACH TO FEATURES OF FORM AND \\ MOVEMENT
}

UMA APROXIMAÇÃO ANALÍTICA AOS ASPECTOS DA FORMA E O
MOVIMENTO

198

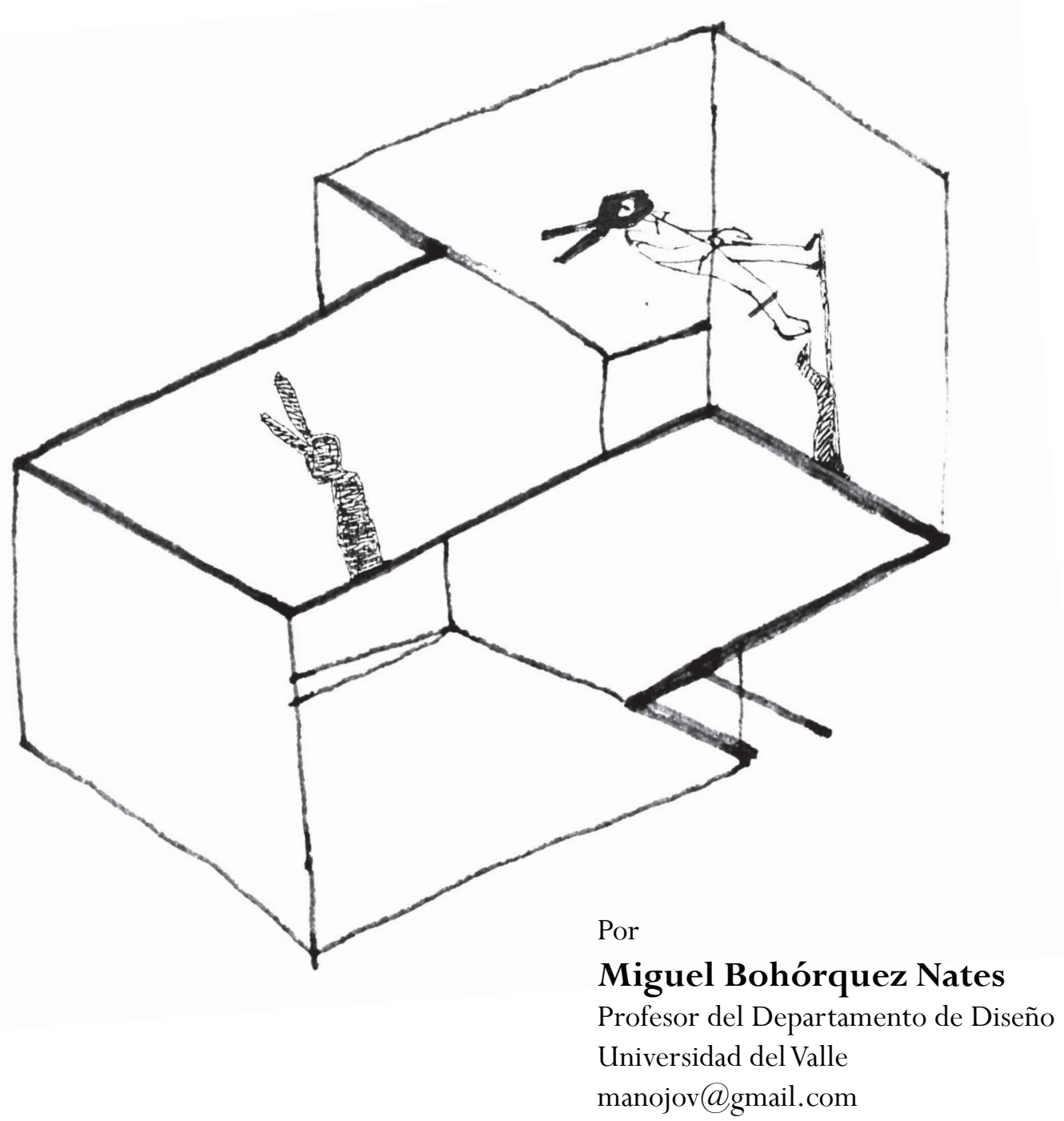


Resumen: En el presente texto expondré una reflexión sobre lo que considero como tres aspectos de la forma que pueden servir como base para un análisis de su actualización en las prácticas de los motiongraphics. La naturaleza dinámica del objeto de esta reflexión exige a su vez el desarrollo del concepto de "movimiento" que trata de poner en diálogo aspectos prácticos de los procesos de diseño con aspectos teóricos que no logran ser operativizados sin sacrificar la complejidad de sus estructuras.

Palabras Clave: forma, configuración, representación,motiongraphics.

Abstract: This articles aims to expose a reflection on three aspects of the way they could serve as the basis for an analysis of the upgrading of practices in motion graphics. The dynamic nature of this matter demands at the same time the development of the concept of "movement", which attempts to relate practical aspects of process design with theoretical aspects that are not operationalized without sacrificing the complexity of their structures.

Keywords: form, configuration, representation, motion graphics.

Resumo: Neste artigo expõe-se uma reflexão sobre três aspectos da forma como eles são a base para uma análise da sua atualização nas práticas dos motion graphics. A natureza dinâmica do objeto desta reflexão exige, na sua vez, o desenvolvimento do conceito de "movimento", que tenta relacionar os aspectos práticos dos processos do design com os aspectos teóricos que não conseguem ser postos em operação sem o sacrifício da complexidade das suas estruturas.

Palavras-chave: forma, configuração, representação, motion graphics.

\section{Introducción}

El hombre se las ha ingeniado para extender su mirada hacia lugares inhóspitos, así se enfrenta a una forma ya no contigua, sino distante, de la cual se apropia y la hace parte de su conocimiento inmediato de lo real. De este modo lo perceptible ya no se limita a la contigüidad física que aprendió durante siglos a decodificar en función de su supervivencia. Ahora las lógicas de supervivencia han trascendido el espacio físico inmediato para expandirse, a través de la imagen en movimiento, hacia espacios inaccesibles al ojo humano que, condicionados por la tecnología, adquieren forma perceptible en tanto fenómenos gracias a procesos fundados en el conocimiento empírico de la realidad y el conocimiento teórico de paradigmas que posibilitan el ordenamiento de nuestra percepción de lo real.

En este contexto la conformación entendida como el proceso de dar forma involucra tres aspectos: uno de naturaleza mental (orden), uno de naturaleza material (fenómeno) y uno de naturaleza simbólica (configuración). En términos de lo mental, refiere la instauración de modos de ver el mundo; en términos de lo material, modos 
de interpretación de los fenómenos percibidos; y en términos simbólicos, supone la ilusión causada por medio de elementos dinámicos de la imagen, entendidos como síntesis de la confluencia de fuerzas espaciales y temporales a partir de las cuales se posibilita y determina los sentidos de la imagen.

La configuración es el aspecto de la forma y relaciona el fenómeno y el orden. El orden es la posibilidad estructurante de operar sobre lo real, y el fenómeno se impone - en su fuerza bruta en tanto hecho, es decir, existencia concreta y actual - frente a lo mental sin dejarle más opción que la construcción de sentido que le otorga un status de objeto a las cosas del mundo. La forma, como configuración, es al mismo tiempo causa y resultado de la asignación de sentido dentro del espectro de transformación de las cosas en objetos, los objetos en utensilios y los utensilios en instrumentos ${ }^{1}$. Esto solo lo hace posible el ser humano en su facultad artificializante de lo real, por medio de la cual convierte los estados más básicos de su condición biológica en necesidades que luego transforma en problemas. Estos problemas adquieren diferentes presentaciones entre las cuales sobresalen las relacionadas con cierta idea de desajuste de la armonía de las situaciones sociales que pueden ser leídas en clave gnoseológica o en terminos morfológicos o "de diseño”. Los aspectos morfológicos suponen consideraciones sobre los valores estéticos, funcionales y simbólicos de los objetos y de la imagen en tanto posibilidades de apertura hacia lo indeterminado en los procesos proyectuales. El diseño es entendido así como la facultad humana para la configuración de posibilidades de existencia.

La forma cabalga con el mismo brío en los terrenos de lo abstracto (lo mental) y en los terrenos de lo concreto (lo real). Estos dos terrenos se pueden entender, según Janello (1980), a partir de una distinción de elementos de sentido de la configuración de los objetos visuales que permite ver dos nociones: una noción morfosintética y una noción morfoanalítica. Para el primer caso hace uso de la lógica y el carácter a priori de modelos como la geometría de donde rescata los conceptos necesarios para la instauración y el uso de lo que algunos han llamado un "lenguaje plástico" y otros como Kepes - han llamado un "lenguaje de la visión" (1944 [1976]).Estos modelos en su capacidad generativa "conjugan el esplendor de la imaginación y la más rigurosa exactitud" en palabras de Roberto Doberti ${ }^{2}$. Para el segundo caso el recurso utilizado está más cercano a la experiencia empírica - la cual se torna significativa - de donde se extraen regularidades que alorganizarse procuran modelos mentales o lo que, tanto Janello como Klinkenberg(1996 [2006], p, 352), llamaron “tipos”. Un tipo, para los dos autores, reúne características esenciales que, en Janello, son esencialmente mórficas y en Klinkenberg son tanto espaciales (físicas) como conceptuales - que permiten crear conjuntos de cosas del mundo. También aquí la imaginación hace posible, aunque de modo diferente, la configurar lo que Gadamer llama "realidades autónomas". En el caso de la noción morfosintética, movimientos como el arte concreto plantearon que toda invención ${ }^{3}$ solo era posible a través de la forma pura. Para el caso de la noción morfoanalítica esta capacidad emancipatoria de la forma se manifestaba por medio del establecimiento de combinaciones que transgredían las normas de organización de lo real que, al lado de la naturaleza inventiva de la forma pura, instaura de modo particular la posibilidad de referirse a un espacio cuya naturaleza es virtual. 
La configuración de la forma a su vez considera la posibilidad de existencia ontológica.

Ya lo decía Kenny en su interpretación de la teoría pictórica del significado de

Wittgenstein "Every picture represents a possible state of affairs, which may be called its sense"

(1973 [2006], p, 47), lo que para Magariños en su visión peirceana es solo un aspecto

de la semiosis de la forma. Magariños (2008) identifica en la forma dos aspectos:uno

predominantemente cualitativo, es decir, la forma como cualidad plástica, y otro

predominantemente simbólico, es decir, la forma como valor cultural construido al

interior de una comunidad determinada (Magariños, 2008, pp 323 - 329).

\section{Aspectos de la forma}

La forma como orden

La forma en un sentido hjelmsleviano podría concebirse como el aspecto del lenguaje,modelos teóricos, que posibilitanciertas operaciones estéticas según un espectro (inestable) de valores contextualmente definidos. Entendida así la forma puede verse como un rasgo y resultado de la dislocación entre la imagen y lo representado que se genera en el proceso de percepción: la imagen retiniana no corresponde especularmente con la realidad ni con la imagen que se aloja en nuestra mente. Esta primera consideración asume la forma como un orden instaurado por medio de modelos teóricos que buscan una representación relativamente estable de la realidad para poder operar sobre ella sin la incertidumbre que genera su naturaleza continua y dinámica. Es gracias a sistemas como la geometría que podemos reconocer figuras estables y manipulables conceptualmente - como el círculo - que en la realidad se presentan de forma accidentada y sobretodo completamente inestable y efímera. El otro factor que posibilita la percepción de objetos como instancias de estabilización provisional de sentido está basado en nuestra experiencia significativa con lo real a partir de la cual se detectan regularidades físicas en las cosas del mundo con las que construimos modelos mentales que organizan lo que se puede entender como los rasgos esenciales comunes de las cosas de lo real ${ }^{4}$. Así se genera una ilusión estabilizadora basada en la memoria visual y el conocimiento de sistemas lógicos que nos hace percibir el mundo de forma ordenada. De lo contrario, la velocidad y la transformación de las imágenes retinianas proyectarían un caos inaprensible. La sensación pura producida por un estímulo visual y albergada en nuestra retina está despojada de toda ilusión, sin embargo esta imagen retiniana es la posibilidad de dicha ilusión como operación mental que dispone el ejercicio de interpretación.

Ese orden instaurado permite organizar la realidad en fenómenos ópticos aislables, destacables, cerrados y estructurados (Katz 1945, p, 50) como formas (en un sentido plástico) reconocibles en el espacio e identificables a partir de operaciones que contemplan conceptos como el de la diferencia y la semejanza. Estas operaciones permiten una organización lógica del espacio a partir de ciertas lógicas espaciales reconocidas en el mundo. Este reconocimiento es posibilitado y determinado por los modelos y lenguajes de representación espacial como la perspectiva y la geometría, más 
o menos normalizados gracias a su incorporación en el uso cotidiano: manifestaciones naturalizadas de la facultad artificializante del ser humano, su "alienación humanizante", como diría Juan Magariños de Morentin (1983,p, 23). Fenómenos como la sección aurea y la serie de Fibonacci constatan lo determinante de estos modelos teóricos en la interpretación de un estado de cosas del mundo. Pero esta naturalización no es más que una ilusión pues como bien reconoce Cassirer los espacios perceptivo y orgánico son definidos por el espacio simbólico que a modo de filtro matiza la experiencia sensible y la acción (1944 [1967], pp, 71 - 89) alejándonos de toda posibilidad de una relación meramente natural con el mundo. La oscilación entre esta ilusión y el uso consciente de los artificios formales que la constituyen es una operación recurrente en el proceso creativo de diseñar, el cual usa la técnica de ensayo/error como unidad metodológica. Para la manipulación de la forma es necesaria cierta cercanía con la pieza en proceso que permite controlar el detalle en su configuración, y para dejar que la ilusión haga lo suyo es necesario que el sujeto creativo establezca una distancia frente a su creación. Ésta es una distancia física y cognitiva pues como decía Gombrich "I cannotmake use ofanillusionandwatchit." (1960 [1969], p 6). En esta distancia actúan los fenómenos de autolvido y la inmediatez, el primero referido a la aparente desaparición de todo conjunto de principios que explicitan la estructura lógica de un lenguaje, el segundo como el eclipsamiento de la forma ocasionado por su significado o su efecto de sentido ${ }^{5}$.

La forma como fenómeno

Los psicólogos de la forma en Alemania (teoría de la Gestalt) a inicios del siglo XX plantearon el "agrupamiento" como el principio básico de la organización de los estímulos visuales. El agrupamiento es un fenómeno físico de la formaque permite reconocer unidades de organización espacial dentro del campo visual perceptible por el ser humano. De esta manera, la forma, es una cualidad natural y externa de la apariencia de las cosas del mundo y adquiere sentido en la experiencia perceptiva llevada a cabo por los seres humanos. A pesar del énfasis en la forma como un fenómeno visual, real, externo al individuo, la teoría de la Gestalt asume la geometría como el sistema imperante en la percepción del campo visual constituido por unidades que pasan por la experiencia primitiva para su formación, pero son determinadas por el artificio abstracto y simbólico. En estas unidades o grupos se observan diferentes grados de formación y densidad según un criterio de color, textura o forma. Los grados de formación parecen estar regidos por una lógica analítica de descomposición de un todo en sus unidades mínimas.Sin embargo plantean que, un énfasis en esas unidades mínimas (si bien son físicas y reales, no teóricas), no aporta mucho al estudio de la percepción según el paradigma del "todo”, y más bien reconocen tres aspectos generales a saber: el campo visual, 
la unidad y la forma. Las unidades o grupos primitivos tienen un fuerte vínculo con la realidad natural del estado de cosas, sin embargo los principios determinados por esa existencia son definidos según la convención instaurada por sistemas de representación y configuración formal. De esta manera el principio de agrupación se organiza según criterios de proximidad, semejanza, cerramiento, continuidad, direccionalidad, pregnancia y experiencia que sirven de base tanto para la comprensión del aspecto natural de la forma como del aspecto artificial de su configuración regida por una función que tiene como base la satisfacción de una necesidad del ser humano.

La forma como configuración

En la configuración de la forma plástica “aparecen” con más evidencia elementos conceptuales como el punto, la línea, el plano y el volumen, a los que se les otorga la accidentalidad de correlatos gráficos (sustancia) con los que se puede operar de manera concreta en la construcción de un orden particular y circunstancial en el espacio como estrategia formal.

El Grupo $\mu$ en su propuesta de organización de los aspectos de la significación plástica plantea que esta se construye a partir del establecimiento de relaciones entre la forma, la textura y el color como objetos semióticos susceptibles de ser analizados en sus planos de la expresión y del contenido. Dentro de su análisis recurren a la triada hjelmsleviana en donde tratan de instaurar la forma como base para la estructuración de la naturaleza continua de la materia y sustancia plásticas. Esta suerte de estructuración además es determinada por las limitaciones del sistema receptor del ser humano el cual permite el acceso a segmentos de un continuum organizados según una lógica de oposiciones y de diferencias, A partir de las oposiciones y diferencias se establece un sistema de relaciones como base para el ejercicio creativo que se alimenta de los repertorios de la realidad y las fuentes inagotables de la imaginación. De esta manera la teoría del color (forma), que incluye el espectro cromático y todo un sistema de relaciones basadas en la dupla conceptual oposición- analogía, posibilita cierto reconocimiento de la existencia de los fenómenos lumínicos (materia) pertenecientes a la realidad y perceptibles a nuestra vista que determinan nuestras impresiones visuales particulares (sustancia) a las cuales incluso les asignamos un nombre gracias al repertorio teórico otorgado por la forma posibilitante ${ }^{6}$.

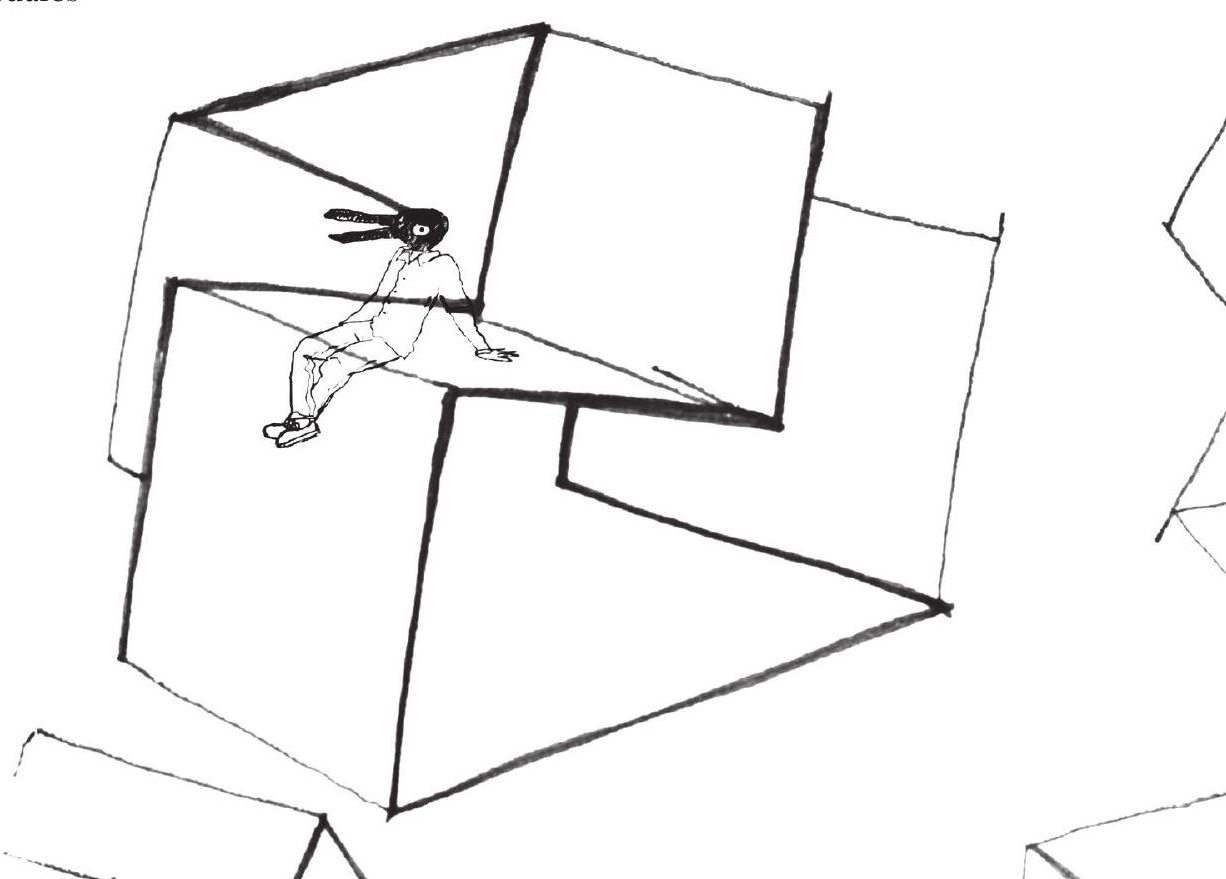


De esta manera la forma se divide en tres aspectos: la forma entendida como modelo teórico instaurador de un orden, la forma entendida como fenómeno visual de la realidad externa, la forma entendida como configuración funcional hecha por el ser humano, fluyendo así como vertiente de sentido que abre las posibilidades del lenguaje en su función de estructuración de lo real. La forma es la base tanto para la construcción de conjuntos de normas estabilizadoras de las fuerzas plásticas como para impulsar líneas de fuga hacia lo indeterminado. La forma como orden, como fenómeno y como configuración se somete así a las barreras marcadas por la filosofía, el arte, la ciencia y la religión (Zátonyi 2007, p, 17-20) y las trasciende al constituirse como núcleo del pensamiento proyectual ${ }^{7}$, porque sirve de sustento perceptible para la prefiguración y la representación como posibilidad de una existencia que aún no es, y que a modo del icono peirceano no es requisito esencial para ser imaginada ${ }^{8}$. De este modo los límites marcados por las barreras se corren en algunos casos y en otros casos sufren perforaciones violentas por donde el sentido se fuga hacia lo que Deleuze y Guattari llamaron otros eslabones semióticos como aglutinaciones y cúmulos de actos de diferente naturaleza que generan y habitan espacios de sentido en donde todo se conecta con todo de una forma orgánica y en un permanente devenir.

En síntesis, la forma en tanto orden posibilita la percepción de los fenómenos del mundo y la configuración interpretativa en sus diferentes manifestaciones de lenguaje; la forma en tanto fenómeno determina y condiciona físicamente la configuración y la instauración de un orden; y la forma en tanto configuración establece la base para la definición de un orden y una interpretación de los fenómenos del mundo.

\section{La forma en movimiento y la forma del movimiento}

Kant en su crítica de la razón pura se refiere al movimiento como un concepto basado en la experiencia empírica soportado en la puesta en relación del espacio y el tiempo que son intuiciones puras. Todo movimiento es movimiento de algo, de una existencia; toda forma es en definitiva una forma en movimiento entendido como cambio en un espacio a través del tiempo. Así el movimiento solo se percibe en el espacio y es condicionado por el paso del tiempo.

El espacio es entendido por Kant como la forma de la experiencia externa. Es una intuición a priori que posibilita la existencia del sujeto, es decir, una representación que posibilita su experiencia externa en el mundo físico. Para Cassirer (1944 [1967],p, 71 - 81) existen tres tipos diferentes de experiencia espacial, a saber, uno orgánico, otro perceptivo y otro simbólico. El espacio orgánico es el espacio de la acción que obedece a una concepción primitiva caracterizada por el arraigo de lo concreto y sustancial en donde no hay lugar para una concepción sistémica que permita elaborar esquemas o modelos de representación espacial. Este espacio orgánico está estrechamente vinculado al sujeto en tanto organismo biológico vivo y a la existencia actual de las cosas, es el aquí y el ahora, es la presentación de lo real, se puede entender como lo que Peirce 
llamaba la "fuerza bruta del hecho" (CP 1.21) y dentro de la categoría de "hecho bruto" propuesta por John Searle (1995 [1997],p, 21, 22) en su planteamiento de la construcción social de los hechos institucionales. El espacio perceptivo es la suma de los elementos pertenecientes a los diferentes géneros de la experiencia sensible, es decir, lo óptico, táctil, acústico y kinestésico. El espacio simbólico es de naturaleza abstracta, podríamos decir que pertenece al mundo de las ideas, es lo imaginario, lugar en donde flotan las representaciones que siguiendo a Sartre (1960 [1964],p, 77-90) participan de cierta dialéctica entre lo ambiguo y lo concreto en donde se reconocen tres aspectos del saber imaginario: uno puro -relaciones abstractas-, uno imaginante -ilustraciones del pensamiento y esquemas simbólicos- y uno lingüístico -la palabra.

El tiempo -volviendo con Kant- es "la condición formal a priori de todos los fenómenos en general” (Kant 1781 [2010], p, 80). Esto quiere decir que incluye la experiencia externa posibilitada por el espacio y que es una intuición interna que determina todos los fenómenos en general.

Cassirer, siguiendo a Kant entiende el tiempo como una condición necesaria para el desenvolvimiento de la vida orgánica. El tiempo entonces es un proceso en el cual se desarrolla la memoria para lo cual es necesario un "orden serial que abarque todos los acontecimientos singulares” posibilitando así su simple reproducción y determinando el elaborado y complejo proceso de reconstrucción de la experiencia. Así podríamos decir que hay una memoria absoluta que sería fácilmente confundible con el concepto de tiempo mismo en tanto orden serial, una memoria fisiológica o perceptiva que daría cuenta de la simple reproducción mental de las sensasiones producidas por los hechos y una memoria simbólica que reconstruiría el sentido de la experiencia proyectándolo hacía otros universos semióticos (Cassirer 1944 [1967], p, 81-89) (Bohórquez, 2014, p, 131).

En un posible recorte del objeto tiempo diríamos que la palabra predomina como registro de la experiencia pasada, el sonido como manifestación concreta del flujo de los hechos actuales, es decir, el presente y la imagen como posibilidad de la proyección de sentido hacia el futuro.

La comprensión de los hechos espaciales se lleva a cabo a través del tiempo ocasionando un movimiento a nivel del pensamiento que determina la transformación de conocimiento. Esta transformación es la concreción del aspecto dinámico del sentido y la definición de un sistema de posibilidades de su proyección. Este carácter dinámico del pensamiento encuentra su correlato en el carácter continuo del mundo real cuya percepción según Georgy Kepes se determina por los siguientes factores naturales (Kepes 1944 [1976], pp, 229-234): la retina como "superficie sensible en que se proyecta el panorama móvil", el sentido del movimiento corporal y la asociación de recuerdos que se articulan en sistemas de códigos que dan cuenta de las leyes generales de la naturaleza física. 
En un intento de organización en grados de complejidad del movimiento, en principio podemos decir que hay algo - no importa que -, una existencia perceptible que en cualquier momento atrae nuestra mirada. Esa atracción es provocada por el movimiento, ese algo está en estado dinámico, o por lo menos así se percibe. Está sometido al cambio de factores espaciales y físicos que actualizados en el tiempo afectan nuestra visión. En este estado lo que percibimos es lo que Arnheim llamaría un “movimiento puro"(1954 [1983], p, 410), es decir la relación dinámica entre dos o más cosas desligada de cualquier sentido más allá del propio movimiento. Este es - albergándonos en el paraguas semiótico del Grupo $\mu$ - el sentido plástico del movimiento despojado de toda iconicidad. Ese algo que es una cosa, o mejor, un conjunto de cosas indeterminado, y esta indeterminación de sentido nos permite la percepción de los valores plásticos del movimiento. Los objetos como estado relativamente estable del sentido a diferencia de las cosas, parecen obedecer a un orden secuencial del paso del tiempo. En su naturaleza utilitaria hacen que el movimiento aquí se transforme en sucesos dejando aparecer la idea de avance ineludible del tiempo en su carácter irreversible. Los sucesos son escudriñados gracias a un repertorio limitado de sentido que permite su organización en secuencias de acciones prácticas. La acción aquí es entendida como el movimiento ordenado bajo una lógica secuencial con un sentido práctico de transformación de lo real en función de la supervivencia. El sentido que trasciende el carácter práctico de la acción se agrupa en el acontecimiento como resultado de una concepción compleja del movimiento de las formas que ya no es más percibido en sí mismo, ni simplemente condicionado por el sentido práctico, sino que ahora es siempre impregnado por el germen de la ideología.

La configuración del movimiento es determinado por aspectos materiales del cuerpo de los objetos que entran en relación y las técnicas de representación. Las artes del movimiento se han encargado de explorar exhaustivamente las posibilidades expresivas de su respectiva corporeidad y sus técnicas específicas. En el campo de lo audiovisual por ejemplo, podemos observar tres tipos de configuración del movimiento: uno relacionado con la captura tecnográfica de fragmentos que sirven como unidades compositivas, otro cuyo sustento es la construcción analítica por medio de la configuración de ciertas unidades mínimas cuya frecuencia produce la ilusión del movimiento, y otro que resulta de una combinación de técnicas agrupadas al interior de estos dos tipos, obedeciendo a lo que algunos han llamado las técnicas expandidas caracterizadas por una suerte de hibridación mediática y tecnográfica.

De los modos de configuración caracterizados por la captura tecnográfica del movimiento podemos mencionar al cine como su medio principal y a la teoría del montaje cinematográfico como el orden que rigió su ejercicio poético por lo menos durante los periodos llamados clásico y moderno después de los cuales las transgresiones a la teoría inicial son tales que surgen otras posibilidades estéticas. El montaje es uno de los cuatro tipos de movimiento según Vivian Sobchack(1982, p,317). Estos cuatro tipos son: el movimiento de los objetos frente a la cámara, el movimiento de la cámara, el movimiento del lente y el movimiento provocado por la yuxtaposición en la etapa de montaje. En este caso la forma como orden se articula a través del modelo teórico del 


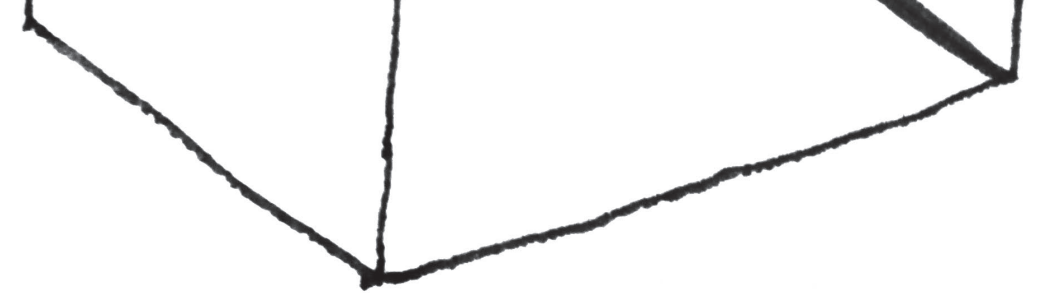

lenguaje cinematográfico, la forma como fenómeno se percibe por medio del cambio del estado físico de las cosas del mundo y la forma como configuración se construye a partir de la puesta en relación de diferentes factores pertenecientes a los aspectos mentales y materiales. El movimiento generado por el lente puede ser considerado como parte de los movimientos de cámara, pues en realidad el efecto dinámico que produce exige un movimiento físico de la pieza constitutiva del aparato. El movimiento de cámara según Sobchack es un "eco de la movilidad esencial de nuestra propia consciencia como es corporeizada en el mundo...” (Sobchack , p, 317), esto quiere decir que cumplen su papel en la concepción del aparato cinematográfico como la representación de los modos de percibir lo real y los modos de imaginar que permitieron al cine clásico conquistar un espacio audiovisualmente habitable en la pantalla para el espectador en la sala de cine. El movimiento de los seres y los objetos frente a la cámara es el mundo pasando frente a la pantalla como ventana hacia lo real. El movimiento creado por la yuxtaposición de imágenes es el grado más alto de la naturaleza discreta de la imagen en el audiovisual, porque no hay rastro alguno de los modos como percibimos lo real o de los modos como lo real se presenta ante nosotros. Hay una ruptura, una dislocación entre la imagen y lo real que es imperceptible gracias a una suerte de naturalización de los códigos de funcionamiento del lenguaje audiovisual que produce un efecto ilusorio.

En este sentido, desde los inicios del cine, parece haberse dado una interesante confrontación entre una supuesta pretensión de reproducción mecánica de la realidad y una función de representación transformadora de las impresiones sensoriales que el ser humano tiene de la realidad. Rudolf Arnheim (1971 [1986],p, 19 - 100) fue uno de los primeros participantes de esta confrontación al exponer su tesis relativa al papel determinante de las limitaciones técnicas del medio cinematográfico - en su supuesta pretensión de reproducción mecánica de la realidad - para la generación de una suerte de repertorio de recursos formales que serviría de base para su instauración como forma artística. En el fondo de la discusión se disputaba la legitimación del cine como forma artística para lo cual se requería distinguir entre una naturaleza reproductora y una naturaleza creadora para determinar a cual de las dos adhería la práctica cinematográfica. El argumento de Arnheim giraba en torno a la demostración de la imposibilidad de una reproducción de la realidad por las limitaciones técnicas del aparato cinematográfico, las cuales provocaban una imagen que en tanto objeto material tenía propiedades diferentes a la realidad representada. Esta diferencia era entendida como ausencia de propiedades y detonó - como en otros momentos históricos y prehistóricos - la exploración formal de nuevas posibilidades expresivas provocando consecuentemente la instauración de una forma de lenguaje. 
Tres de las ausencias que aún hoy se mantienen son: la delimitación de la imagen y distancia del objeto, la ausencia del continuo espacio - tiempo y la ausencia del mundo no visual de los sentidos. La respuesta a estas ausencias tiene su base operativa en el montaje, el cual adquiere un valor que supera en gran medida el que tendría como reproductor de la realidad factual. Esta soberanía del montaje, como lo menciona Metz (1968 [2002], p, 57), convierte a la fragmentación espacial y temporal de la realidad en una necesidad estética más que una necesidad técnica para poder proponer una configuración de la acción dramática por medio de la manipulación de secuencias de imágenes que de otra forma se presentarían como una simple sucesión de pequeñas situaciones cuyo valor estético podría desvanecerse en la indiferencia de la percepción cotidiana. De este modo la operación adquiere su valor más allá del acto estético que desemboca en el uso de figuras retóricas y puede trascender en la instauración de un lenguaje estético. Ese valor a su vez se produce a partir de una dislocación entre el acto y el lenguaje estético provocado por la misma práctica artística.

Todo acto de creación implica una dislocación de la realidad, toda instauración de una forma de lenguaje implica la dislocación de la realidad.

La tendencia a una construcción analítica del movimiento tiene en el conjunto de técnicas de animación su más claro exponente. Aquí el movimiento surge ya no como una restitución en la pantalla de una serie de imágenes capturadas, sino como generación cuadro a cuadro de la imagen asumiendo el fotograma como unidad temporal y espacial. En este caso las formas adquieren su existencia por medio de un procedimiento de elaboración gráfica de la imagen en donde el sujeto-autor entra en diálogo con la línea en su propósito de crear no solo la ilusión de movimiento sino la ilusión de vida. La animación está vinculada estrechamente con la representación del movimiento, sin embargo este es solo un medio para alcanzar la ilusión de estar observando una suerte de conciencia en la pantalla como su propósito real en términos representacionales. Para este propósito el movimiento resulta ser una suerte de grado más bajo de animación en donde lo que se representa son los valores plásticos del cambio 9 . Un simple desplazamiento, un cambio de luz que nos permita percibir variaciones de color como manifestaciones de las relaciones dinámicas

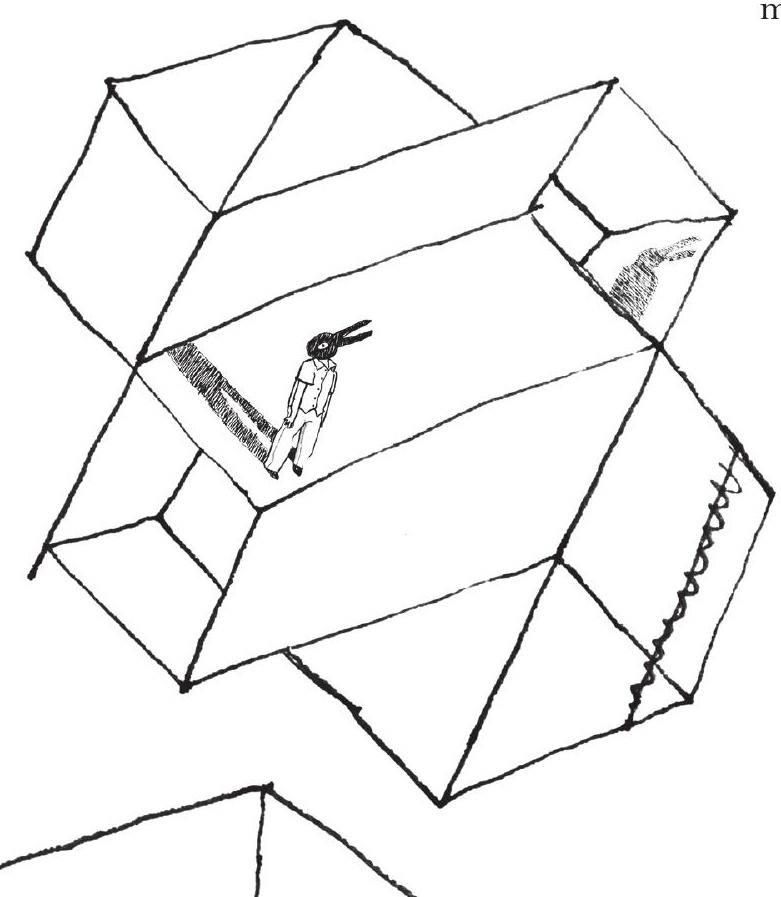
entre las formas sin que aún logren un estatuto objetual, lo que convertiría al simple movimiento en acción, como la acción del semáforo cuando cambia la luz de verde a rojo que es posible gracias a que hay verde, hay rojo y hay cambio. Las acciones además de fenómenos en donde se ven involucrados objetos pueden también ser ocasionados por los seres que se mueven al interior del 
encuadre, en este momento estamos hablando de animación en forma literal como la representación del movimiento que es ocasionado por la motivación interna de un personaje como respuesta a una exterioridad que lo incita, o mejor dicho lo obliga a actuar. Esta actuación al tener una motivación interna está estrechamente relacionada con un estado emotivo o un estado mental que se proyecta por medio del comportamiento corporal.

Las diferentes técnicas, a pesar de tener en común la idea de la creación minuciosa de imágenes en movimiento que representan el comportamiento dinámico de los cuerpos y la conciencia de los personajes, conservan leves diferencias en tanto actualizaciones concretas y particulares de los principios de la animación. Así podemos organizar las técnicas en un espectro que vaya desde la creación de formas abstractas en movimiento hasta la construcción cuadro por cuadro por medio de la captura fotográfica. Este espectro, a su vez, se puede dividir en dos tipos de imágenes si hacemos énfasis en el salto dimensional del 2D al 3D y podemos también hacer otra distinción basada en la naturaleza de las tecnologías que determinan la existencia de las imágenes animadas analógica o digitalmente. De las técnicas entonces podemos decir que el dibujo animado - desde los rayones directamente sobre la película hasta el dibujo figurativo sobre acetatos - es una representación quirográfica elaborada en un diálogo riguroso con el trazo sobre la superficie en donde el sujeto usa las extensiones objetuales con las que se sienta más cómodo para imprimir su sensibilidad y su pensamiento. En el dibujo animado existe la posibilidad de crear fotogramas clave - que son poses representativas del personaje en donde se marca un antes y un después de un movimiento particular - y luego dibujar las poses intermedias. De esta forma se hace una especie de estructuración temporal del movimiento controlando el número de dibujos que se harán para una acción particular. Así el dibujo de los fotogramas clave se puede entender como la última etapa del proceso de prefiguración que inicia con la elaboración de un storyboard. Esta posibilidad no existe en otras técnicas como el stopmotion, en donde la única opción es lo que se llama animación straightahead que consiste en mover paulatinamente los objetos para ser fotografiados cada vez en una posición levemente diferente a la anterior según el efecto de velocidad que quiera lograrse. Así esta etapa de prefiguración del movimiento es eliminada, dejando como única opción la prefiguración mental sobre la base de un modelo (personaje) y un storyboard de la secuencia a realizar. De esta manera la configuración del movimiento es un procedimiento que no tiene el control del dibujo animado en términos de la duración y el efecto de velocidad y aceleración. En el stopmotion se da ese salto dimensional del 2D al 3D pasando de dibujar el movimiento a mover los modelos paulatinamente frente a una cámara que registra cada cambio físico secuencialmente. Según el criterio de la dimensión, entre el dibujo animado y el stopmotion hay una técnica llamada animación por recortes en donde la forma se logra a partir de planos de papel recortados para elaborar representaciones figurativas o abstractas que se desplazan sobre una superficie plana y se capturan del mismo modo que en el stopmotion. Otra técnica que logra la ilusión de movimiento del mismo modo es la pixilación, que se puede considerar un derivado del stopmotion con una diferencia: lo que se captura no es un modelo, sino un personaje de carne y hueso. Aquí la figura del 
animador es relegada a la secuencialización posterior en un software de composición o de edición digital y a las indicaciones que pueda hacerle al actor sobre la base de una secuencia de acciones proyectadas en el storyboard. En esta técnica la sustancia de la expresión es la gestualidad del cuerpo humano cuyo movimiento no es capturado en su estado natural de continuidad, sino que es construido a partir de la captura cuadro a cuadro de las diferentes poses.

La combinación de las técnicas agrupadas en los dos aspectos anteriores de la configuración del movimiento dan como resultado manifestaciones de formas de lenguaje como los videoclips y los motiongraphics que encuentran en la composición su forma natural de hacer operaciones morfosintácticas. La composición según Manovich (2001, p.130) es esa operación donde se combina todo tipo de secuencias de imágenes e imágenes fijas para la constitución multicapas de una sola secuencia. La configuración en este caso se basa en la puesta en relación espacial y temporal de secuencias y elementos previamente producidos regidos por normas de composición para pantalla. Para un entendimiento de los aspectos formales de los motiongraphics se puede partir de la presentación de los conceptos de espacio, tiempo y movimiento hecha en párrafos anteriores como base para un pequeño despliegue analítico de lo que considero sus tres grupos de elementos constitutivos, a saber, la imagen, el sonido y la tipografía. De esta forma construimos una pequeña clasificación de los aspectos espaciales, temporales y dinámicos de la imagen, el sonido y la tipografía.

Así podemos decir que un análisis de la naturaleza espacial de la imagen se puede iniciar con el reconocimiento de las posibilidades de configuración del color, la textura y la forma dentro de los límites físicos del formato para obtener como resultado el encuadre como unidad espacial estable. En términos temporales estas posibilidades se actualizan por medio de lo que podríamos llamar un orden de lectura, que obedece a estructuras de organización de las impresiones que constituyen un campo visual, que adquieren una duración organizada por medio de una dialéctica entre la estabilidad espacial de los encuadres y la transición dinámica que los conecta en el tiempo, conformando así el plano.Y finalmente la duración es condicionada por la relación entre el número de fotogramas que se proyectan en un segundo, lo que da como resultado la ilusión de diferentes tipos de movimiento ${ }^{10}$ que organizados en una secuencia de planos constituyen las secuencias como unidades de contenido.

El sonido por medio del timbre, la intensidad y la altura establece un espacio acústico en el cual se organiza una duración según pulsos y secuencias de compases a modo de órdenes cíclicos sobre los cuales se construyen variaciones rítmicas en un juego de cadencias y velocidades que sirven de base para el flujo de una o varias líneas melódicas. La tipografía se organiza espacialmente según relaciones entre forma y contraforma de donde surgen las diferentes posibilidades cualitativas de la letra que se actualizan según los aspectos relacionales como el espaciado, el tracking, el kerning y el interlineado para producir diferentes grados de legibilidad según la dirección, la orientación, la proximidad y el agrupamiento de palabras en la conformación de textos. 
La forma como orden en estos casos es la posibilidad de la existencia tecnológica que a su vez determina el ejercicio de configuración del movimiento. En la configuración, se pone a prueba el lenguaje por medio del conocimiento técnico.

\section{Conclusión}

Para finalizar podemos decir que un estudio de la forma y el movimiento en el ámbito de los motiongraphics puede abordarse desde los aspectos presentados anteriormente como base para el estudio de las relaciones que ella establece con lo imaginario, lo real y lo simbólico como aspectos del contenido, el cual adquiere sentido según los contextos particulares de su existencia concreta en donde puede obedecer a una dinámica de ordenamiento regida por los conceptos de género y estilo como prolongaciones culturales de lo mediático y lo estético. Sus posibilidades de concretar el movimiento en pantalla, trascienden las lógicas realistas y naturalistas de ilusión de habitabilidad visual de la imagen por medio de otros modos de puesta en relación del espacio y el tiempo que obedecen a diferentes grados de abstracción instaurando sus propias lógicas internas de funcionamiento de la forma. Estas lógicas apuestan a otras formas de alcanzar la continuidad y la discontinuidad del flujo de imágenes en pantalla, y se proponen como una actualización de operaciones formales en la pantalla. En esta actualización se resignifican los tipos de movimiento mencionados por Vivian Sobchak por medio de la transformación de algunos recursos estilísticos del montaje, el plano secuencia y la composición en pantalla.

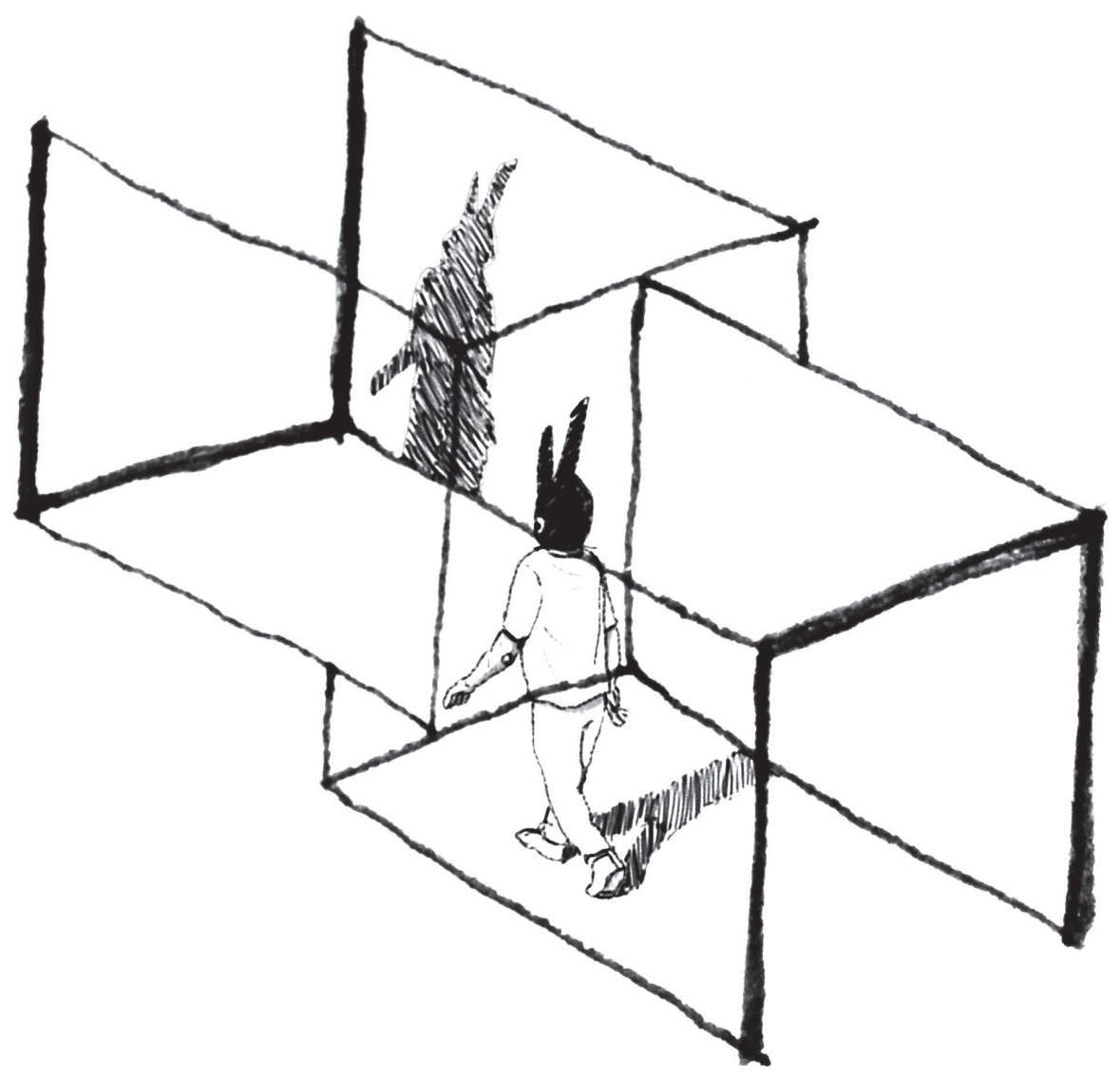




\section{Notas}

${ }^{1}$ Esta idea del paso de las cosas a los objetos fue expuesta por Roberto Doberti durante una de las sesiones de clase y es desarrollada en "Conformación - bases para el reconocimiento de la condición constitutiva y determinante de la forma”, uno de los textos de su autoría usados como bibliografía del seminario Lógicas de la forma dictado en 2012 en el doctorado FADU - UBA.

${ }^{2}$ En "Forma y geometría - Lógica interna y lógica de aplicación", bibliografía para el seminario Lógicas de la forma dictado en 2012 en el doctorado FADU.

${ }^{3}$ Me refiero aquí a los representantes del arte concreto en Argentina quienes se comprometieron con la búsqueda de una desmantelación del espacio ilusorio como renuncia a todo aspecto representacional de la pintura (Maldonado 1948 [2003]).

${ }^{4}$ César Janello - como se presentó en líneas anteriores - hablaba de las formas morfosintéticas y los tipos morfoanalíticos. Estos segundos estaban basados en nuestra experiencia empírica (1980).

${ }^{5}$ El concepto de autolvido es uno de los fenómenos a los que Gadamer se refiere como lo propio del lenguaje, los otros dos fenómenos son: su carácter dialógico y la universalidad (1986 [1998], p, 149). El concepto de inmediatez que uso aquí está basado en uno de los aspectos del simbolismo inconsciente de Hegel con el cual se refiere a la unidad entre alma y cuerpo; el concepto y la realidad; lo corporal y lo sensible; lo natural y lo humano concebida por las primeras civilizaciones (1989,p, 287, 288).

${ }^{6}$ En este fragmento intento poner en diálogo la triada hjelmsleviana con la triada peirceana adaptando un ejemplo en donde el grupo $\mu$ hace una aplicación de los tres conceptos de Hjelmslev al plano de la expresión del color como objeto semiótico (Grupo $\mu$ 1993, p.171).

${ }^{7}$ En realidad es la morfología entendida como el estudio y la producción de formas la que según el planteamiento de Roberto Doberti es núcleo disciplinar del proyecto como cuarta posición, al lado de la ciencia cuyo núcleo es la matemática, el arte cuyo núcleo es la abstracción y la tecnología cuyo núcleo es el mecanismo.

${ }^{8}$ Peirce dice que el icono como aspecto del signo a pesar de que tiene un vínculo con su objeto según un criterio de semejanza, no necesita de la existencia de este para cumplir su función semiótica porque lo que representa es una posibilidad lógica (C.P. 2.247).

${ }^{9}$ Chris Webster propone cuatro grados de animación que van desde la representación de actividades despojadas de todo valor icónico hasta la actuación como grado más alto en donde el objeto de representación es el estado sicológico de los personajes (2005, p, 69 - 71).

${ }^{10}$ Los ya mencionados en párrafos anteriores según un interpretación del planteamiento de Vivian Sobchak.

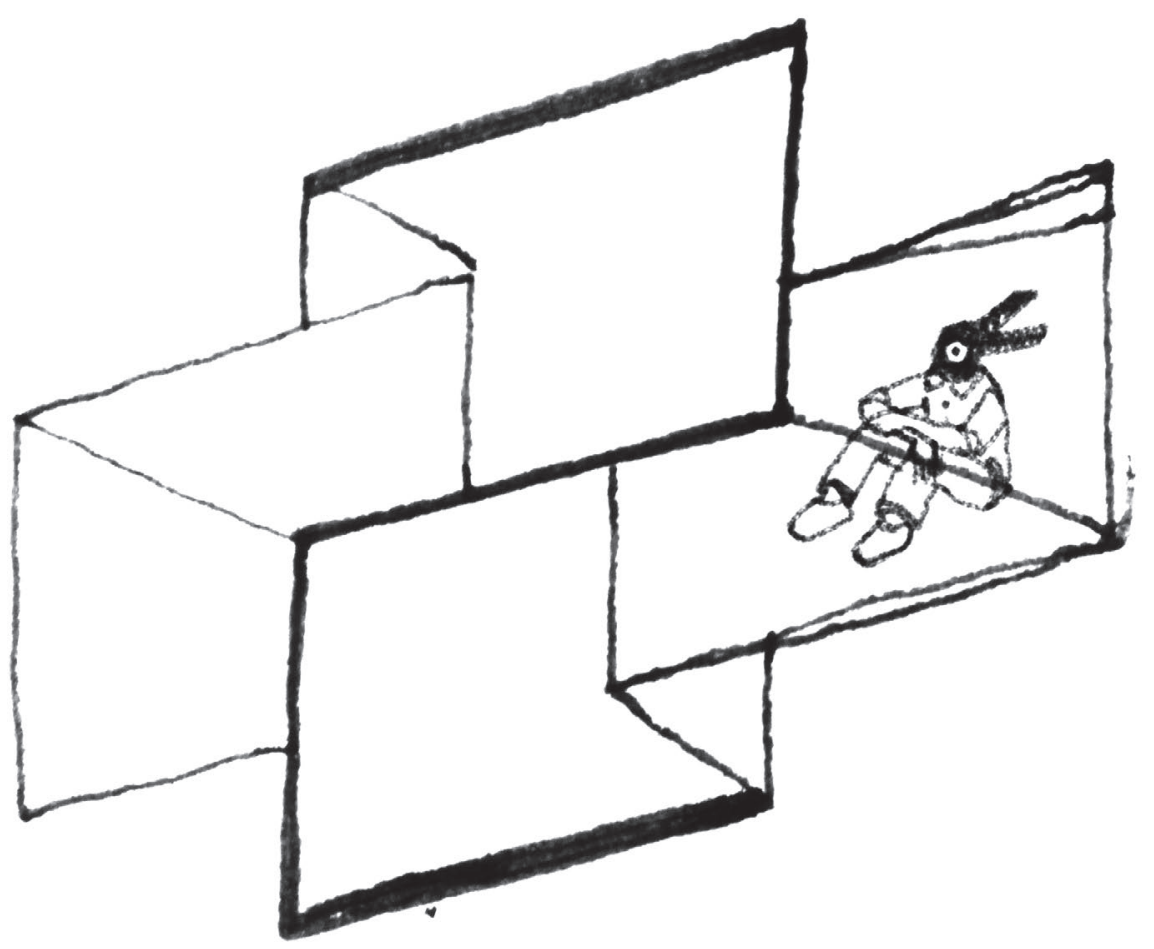




\section{Referencia}

Arnheim, Rudolf. (1954) Arte y percepción visual. Psicología del ojo creador. Alianza Editorial 1983. .(1971) El cine como arte, ediciones Paidós 1986.

Bohórquez Nates, Miguel. (2014). Los motion graphics como forma de lenguaje. En Claudio Guerri, Nonágono Semiótico. Un modelo operativo para la investigación cualitativa (pp. 127 - 139). Buenos Aires, Eudeba.

Cassirer, Ernst. (1944). Antropología filosófica. Fondo de cultura económica, 1967.

Doberti, Roberto. (2012). "Conformación - bases para el reconocimiento de la condición constitutiva y determinante de la forma". "Forma y geometría - Lógica interna y lógica de aplicación". "La morfología: núcleo del proyecto”. Textos del seminario Lógicas de la forma dictado en el doctorado FADU - UBA, Buenos Aires.

Gadamer, Hans George. (1986). Verdad y Método II. Ediciones Sígueme, 1998.

GOMBRICH, Ernst. (1960). Art and Illusion - A Study in the Psychology of Pictorial Representation, Princeton University Press, 1969.

GRUPO $\mu$ (1993)El tratado del signo visual, Ediciones Cátedra.

Hegel, G.W.F. 1989. Lecciones de Estética -Volumen I. Ediciones Península.

Janello, Cesar. (1980. “Diseño, Lenguaje y Arquitectura”, Buenos Aires: Textos de Cátedra, FADU -

UBA, mimeografiado.

Kant, Immanuel. (1781). Crítica de la razón pura. Aguilar 2010.

Katz, David. (1945). Psicología de la forma. Editorial Espasa - Calpe.

Kenny, Anthony. (1973).Wittgenstein. Blackwell Publishing 2006.

Kepes, Gyorgy. (1944). El lenguaje de la visión. Ediciones Infinito 1976.

Klinkenberg, Jean Marie. (1996). Manual de semiótica general. Universidad Jorge Tadeo Lozano 2006.

Magariños, Juan. (1983). El Signo - Las fuentes teóricas de la semiología: Sausssure, Peirce, Morris. Hachette. . (2008). La semiótica de los bordes. Comunicarte, Córdoba - Argentina.

Maldonado, Tomás. (1948). El arte concreto y el problema de lo ilimitado. Notas para un estudio teórico. Zurich. Ramona, Buenos Aires, marzo de 2003.

Manovich, Lev. (2001). El lenguaje de los nuevos medios. Paidós, Barcelona.

Metz, Christian. (1968). Ensayos sobre la significación en el cine (1964-1968), volumen I. Ediciones Paidós Ibérica, 2002.

Peirce, Charles. (1931-58). Collected Papers of Charles Sanders Peirce, Vols. I-VI ed. Charles Hartshorne and Paul Weiss. Vols. VII-VIII ed. Arthur W. Burks. Cambridge, MA: Harvard University Press.

Sartre, Jean Paul. (1960). Lo imaginario. Editorial Losada, Argentina 1964.

Searle, Jhon. (1995). La construcción de la realidad social. Paidós 1997.

Sobchack, Vivian. (1982). "Toward inhabited space: The semiotic structure of camera movement in cinema” en revista Semiótica Volumen $41-1 / 4$, págs. 317 - 335.

Webster, Chris. (2005). Animation: the mechanics of motion. Focal Press.

Zátonyi, Marta. (2007). Arte y Creación. Los caminos de la estética. Capital Intelectual.

Recibido: octubre 30 /Aprobado: noviembre 30 de 2015 